\title{
AS TEORIAS DA APRENDIZAGEM NO CONTEXTO DA EDUCAÇÃO A DISTÂNCIA
}

\author{
Jefferson Mercadante \\ Kátia Duarte Magalhães \\ Laudicéia Aparecida Gildo
}

\section{RESUMO}

Este trabalho tem como base uma pesquisa bibliográfica acerca das teorias da aprendizagem em sua relação com a educação a distância. O objetivo do estudo foi investigar as implicações das teorias da aprendizagem na relação tutor-aluno. Para tanto, realizou-se uma revisão da literatura acerca das questões de planejamento, implementação e gestão da EaD e dos Sistemas de Tutoria em cursos a distância. Em um segundo momento, listou-se as competências necessárias aos tutores virtuais e se descreveu os principais conceitos de três diferentes abordagens da aprendizagem: a teoria sociointeracionista de Vygotsky, a pedagogia humanista de Paulo Freire e a psicanálise enquanto teoria que pode vir a orientar a compreensão de questões afetivas e interativas que envolvem tutor e aluno no processo de ensino e aprendizagem a distância. Por fim, analisou-se por meio de questionário, como as teorias de aprendizagem se aplicam à prática da tutoria virtual. Concluiu-se que, para além das competências técnicas da função de tutoria, o papel do tutor no ensino a distância requer o conhecimento teórico pedagógico e se observou que tais características podem ser desenvolvidas por meio de programas de formação e treinamento de tutores que incluam em seu escopo o estudo sobre as teorias da aprendizagem.

Palavras-chave: Educação a distância. Teorias da aprendizagem. Relação tutor-aluno.

\section{INTRODUÇÃO}

Falar em teorias da aprendizagem no contexto da educação a distância (EaD) implica uma incursão na atuação do tutor. Oliveira (2002 apud PRETI, 2003) verificou a relevância do tutor para a $\mathrm{EaD}$ em análise dos cursos de formação de professores de cinco instituições pioneiras no contexto dessa modalidade de ensino no Brasil. O levantamento documental realizado por Oliveira (2002 apud PRETI, 2003) revelou que, apesar da nítida importância atribuída ao papel do tutor na $\mathrm{EaD}$, as concepções metodológicas e pedagógicas de cada sistema de tutoria se diferenciam, passando por abordagens construtivistas, sociointeracionistas, condutistas e humanistas. Podemos depreender que os sistemas de tutoria revelam, na prática, a concepção de EaD da instituição enquanto estruturação de sistemas de apoio aos estudantes. Nesse sentido, vale a consideração de Oliveira (s.d., p. 2): "E quem melhor representa a instituição para o estudante? (...) O tutor.".

Portanto, tal como apontam Belloni (2006 apud CAVALCANTE FILHO; SALES; ALVES, 2012) e Rodriguez (1993 apud PRETI, 2003), em todos os estudos sobre EaD é consenso afirmar a influência que o papel da tutoria exerce no desempenho da aprendizagem e na taxa de evasão, de tal modo que convém indagarmos: Qual a 


\section{SEMINÁRIO DE PESQUISA EM CIÊNCIAS HUMANAS - SEPECH \\ Humanidades, Estado e desafios didático-científicos \\ Londrina, 27 a 29 de julho de 2016}

importância e como as teorias da aprendizagem se inserem na relação tutor-aluno no contexto da educação a distância? As teorias são fundamentais na construção do sistema de tutoria, definindo o tipo de relação que se pretende estabelecer entre tutor, aluno e material didático.

Tendo como ponto de partida essa indagação, o objetivo do estudo foi investigar as implicações das teorias da aprendizagem na relação tutor-aluno, considerando que o processo de ensino e aprendizagem em EaD envolve particularidades psicossociais que podem potencializar ou dificultar a construção do conhecimento, dependendo do conhecimento que os tutores possuem acerca do conhecimento pedagógico.

\section{A ABORDAGEM SOCIOINTERACIONISTA DE VYGOTSKY EM SUA RELAÇÃO COM A EAD}

Pensando na importância e na necessidade do tutor de conhecer algumas das teorias de aprendizagem, a teoria de Vygotsky pode colaborar para o melhor desempenho do trabalho do tutor, principalmente quando fala-se em afetividade, já que:

Segundo Vygotsky (1993, p. 129), qualquer que seja a forma do pensamento - representações afetivas, imaginação, fantasia ou o pensamento lógico - tem em sua base uma emoção, pois "o pensamento propriamente dito é gerado pela motivação, isto é, por nossos desejos e necessidade, nossos interesses e emoções". (OLIVEIRA, 2009, p. 5).

Dessa forma, Oliveira (2009), reforça a importância da dinâmica dos ambientes de aprendizagem e da linguagem para a mediação, que assume papel de destaque para o aprendizado, uma vez que "é no significado que se encontra a unidade das duas funções básicas da linguagem: o intercambio social e o pensamento generalizante" (OLIVEIRA, 2010, p. 48). Para Vgotsky, ao se utilizar da linguagem o ser humano é capaz de pensar de uma forma que não seria possível se ela não existisse (OLIVEIRA, 2010, p. 51).

Assim, é possível reafirmar que o papel do tutor é de extrema importância no processo de ensino e aprendizagem e também para a melhoria da qualidade dos cursos a distância. Somente uma aprendizagem significativa pode promover, de fato, $\mathrm{o}$ aprendizado e a linguagem tem um papel determinante que, nos cursos $\mathrm{EaD}$, deve ser vista com mais cuidado, já que a comunicação se dá por meios tecnológicos e pode incorrer em erros de interpretação.

A função de tutor se torna peça chave na relação interativa de troca de saberes, no processo de ensino e aprendizagem do aluno que deve ter autônomo e "dirige" seu próprio desenvolvimento. Um tutor deve saber diferenciar e sequenciar as diversas informações que proporciona aos estudantes, sistematizando suas ações e estar atento a alguns procedimentos, como atuar na função de mediador; conhecer a realidade dos alunos; oferecer possibilidades de diálogo, saber ouvir, ser empático e manter uma atitude de cooperação; oferecer experiências de melhoria de qualidade de vida, de participação e de tomada de decisões (SOUZA et al., 2004).

Teixeira, Costa e Silva e Cordeiro (2013), falam da necessidade de uma formação do professor-tutor, questionando se esses profissionais estão sendo devidamente formados para atuar como formadores em uma perspectiva colaborativa. 


\section{SEMINÁRIO DE PESQUISA EM CIÊNCIAS HUMANAS - SEPECH \\ Humanidades, Estado e desafios didático-científicos \\ Londrina, 27 a 29 de julho de 2016}

Analisam o processo formativo, abordando três cursos de formação, e também sugerem uma proposta formativa para profissionais que têm interesse em atuar na educação a distância, baseando-se na aprendizagem colaborativa, na interação e na aprendizagem significativa. Para Vygotsky (1998), o meio influencia no desenvolvimento e na construção do conhecimento, dessa forma as interações dos alunos no ambiente virtual podem favorecer o seu aprendizado ou não, caso essa interação não ocorra de forma satisfatória.

Segundo Resende (2005), por meio da internet e outras ferramentas tecnológicas é possível propiciar uma experiência de aprendizagem privilegiando a aprendizagem significativa, a interação com o ambiente social e a formação de comunidades para a construção do conhecimento, baseadas nas teorias Sócio-histórico-cultural e Construtivista. Cabe ao educador utilizar os fundamentos teóricos para definir as estratégias pedagógicas adequadas à metodologia de $\mathrm{EaD}$ e ao uso das tecnologias, de acordo com as necessidades dos alunos, provocando a sua capacidade de pensar, agir, construir e reconstruir suas estruturas mentais.

Vygotsky, preocupa-se com a interação social, "pois através das trocas do sujeito com o outro e o objeto social se originam as funções mentais superiores. O indivíduo herda, ao nascer, a evolução cultural e desenvolve-se em função do meio social, o indivíduo é interativo" (apud RESENDE, 2005, p. 2).

\section{A Pedagogia humanista de PAUlo Freire EM SUA RELAÇÃo COM A EAD}

A perspectiva de Paulo Freire "coloca o aprendiz como sujeito" (FREIRE apud FARIA, 2010). Partindo desse princípio, podemos depreender, segundo Faria (2010) e Freire (1979), que o ambiente de aprendizagem virtual, apoiado pelos tipos de mídias, depende muito do aluno, da disciplina e organização deste, mas depende muito também do tutor e todas as responsabilidades inerentes ao papel deste no ambiente de aprendizagem em $\mathrm{EaD}$.

O pensamento de Freire é provocativo, pois estimula a autonomia na formação dos professores para o desenvolvimento de práticas inéditas, viáveis e transformadoras da realidade. Pode-se dizer que essa ideia se comparada à atuação do tutor na EaD está posta em prática. $\mathrm{O}$ tutor se utiliza de diversas ferramentas até então inéditas- como vídeos, fóruns, envio de emails, para transformar a realidade de muitos alunos, para estimulá-los à continuidade do estudo. É necessário ressaltar que depende-se fundamentalmente da ação humana do sujeito que se mobiliza, que acompanha os estudantes e que atende aos alunos de maneira personalizada e que preocupar-se com o ensino e seu resultado para o estudante - o tutor.

Freire destaca a figura do professor como fundamental no processo educativo, também a necessidade de sua formação permanente. Assim deveria ser como os tutores, que são fundamentais à formação do aluno. Entretanto, sabemos que em muitos sistemas de tutoria, os tutores não são formados na área das disciplinas tutoradas, configurando em um distanciamento entre a teoria e a prática enfatizada por Freire.

A contribuição da pedagogia humanista de Paulo Freire na EaD vem no sentido de firmar o papel imprescindível do tutor para a formação do aluno, uma vez que depende deste profissional a construção de novos meios de conhecimento, que não 


\section{SEMINÁRIO DE PESQUISA EM CIÊNCIAS HUMANAS - SEPECH \\ Humanidades, Estado e desafios didático-científicos \\ Londrina, 27 a 29 de julho de 2016}

reproduzam meramente a dependência do aluno ao conhecimento do professor, que instigue, estimule e provoque o aluno ao aprendizado desenvolvido com autonomia, criatividade e curiosidade, que mostre ao aluno que é possível se desenvolver e aprender com autonomia através de aprendizado pautados em reciprocidade, coletividade e solidariedade.

\section{AS RELAÇÕES ENTRE PSICANÁLISE E EDUCAÇÃO ONLINE}

$\mathrm{Na}$ educação online, o tutor virtual torna-se o incentivador da inteligência coletiva, enquanto o aluno tem sua participação representada nos fóruns de discussão, chats, comunidades práticas, teleaulas, avaliações online e outras atividades disponibilizadas no ambiente virtual de aprendizagem. Somente a partir da construção dessa relação entre os sujeitos do ensino e da aprendizagem, o aluno pode ser considerado presente e se encontra como sujeito atuante no processo ensinoaprendizagem (PESSOA; BORGES, 2013).

Considera-se, pois, que o processo de aprendizagem em EaD vai além das questões espaço/tempo, pois envolve particularidades psicossociais que podem dificultar ou colaborar para a construção do conhecimento ao incorporar questões afetivas e interativas desse processo. No entanto, ainda são poucos os estudos que abordam a influência da Psicologia na evolução da educação a distância.

Desse modo, parte-se da função do conceito psicanalítico de transferência e seus efeitos no processo ensino-aprendizagem com a finalidade de contribuir para a melhor compreensão da relação entre tutores virtuais e alunos na educação online e suas consequências na formação do desejo do aluno pelo conhecimento. De acordo com a literatura que investiga as relações entre psicanálise e educação, é preciso que o professor se coloque para o aluno, através do recurso da transferência, na posição de "suposto saber" (PESSOA; BORGES, 2013). Essa transferência, de caráter inconsciente, ocorre no espaço vazio entre o desejo do professor, que não sabe o que o aluno quer saber, e o aluno, que supõe que o saber buscado está no professor. Nesse sentido, é da transferência que o professor pode extrair sua potência de transmissão simbólica do conhecimento como desejável (PESSOA; BORGES, 2013).

Nesse sentido, é preciso considerar, contudo, dois elementos do ensino a distância: a ausência dos sinais visuais e a constituição da linguagem textual virtual. Pallof e Pratt (2004 apud PESSOA; BORGES, 2013), afirmam que tanto o aluno virtual como o professor devem sentir-se à vontade com a ausência dos sinais visuais e devem ser capazes de lidar com questões emocionais sob a forma textual, criando a sensação de percepção de presença virtual. Afirmam ainda que os educadores devem construir um clima de confiança, abertura e autonomia para que os alunos possam sentir-se seguros com relação à forma como são percebidos no grupo. Assim, um dos maiores desafios na modalidade de educação a distância é o de possibilitar condições para que os professores ausentes fisicamente se tornem presentes na virtualidade.

A teoria psicanalítica concebe, ainda, o inconsciente e as suas implicações na construção do sujeito, o que contribui para o desenvolvimento de uma proposta de aprendizagem na qual o sujeito é considerado ativo, autor de sua história. Somente a partir desses princípios, uma comunicação ativa e produtiva poderá ser desenvolvida, permitindo a aprendizagem em comunidade. Torna-se também necessário o 


\section{SEMINÁRIO DE PESQUISA EM CIÊNCIAS HUMANAS - SEPECH \\ Humanidades, Estado e desafios didático-científicos \\ Londrina, 27 a 29 de julho de 2016}

desenvolvimento da capacidade de reflexão e análise crítica para que os alunos possam dialogar com os professores, elaborar questionamentos e construir novos significados para os conteúdos.

Para a psicanálise, sujeito e desejo são a mesma coisa: só há sujeito quando ele emerge como desejo único e singular. Disso deriva uma recomendação a analistas e professores - muita atenção à tendência de padronização vigente na educação em todos os níveis. Em nome da necessária adoção das novas tecnologias, exclui-se $\mathrm{o}$ sujeito. (PESSOA; BORGES, 2013, p. 118).

Entretanto, segundo Pessoa e Borges (2013), é importante que os educadores consigam reconhecer que os sentimentos que lhes são dirigidos pelos alunos não estão necessariamente voltados à sua pessoa e que essa relação é diferente das demais que estabelece em sua vida. Essa compreensão poderá evitar enganos muito comuns de serem observados na relação professor-aluno tanto na sala de aula presencial como nos ambientes online dos cursos a distância. Além disso, certamente possibilitará atuação mais produtiva e menos conflituosa do educador no processo ensino-aprendizagem.

\section{RESULTADOS E DISCUSSÕES}

Trataremos aqui da descrição dos dados e discussão dos resultados coletados a partir de questionário elaborado através da ferramenta Google Drive Forms e disponibilizado virtualmente a trinta tutores de $\mathrm{EaD}$ de diferentes instituições.

A primeira pergunta procurou saber qual a origem da instituição em que os tutores atuavam e como resultado, tivemos que a maioria dos tutores, 67\%, atuam apenas em instituições públicas, menos de um terço dos respondentes, 27\%, atuam somente em instituições privadas e 6\% atuam tanto em instituições privadas quanto públicas. Esse dado é fundamental para, a partir do cruzamento com os dados que seguem das outras questões, pensar na configuração dos Sistemas de Tutorias em instituições públicas comparativamente aos de instituições privadas.

Em relação ao tempo de atuação como tutor, a segunda questão aferiu que, apenas $17 \%$ dos respondentes atuam na função há mais de cinco anos, enquanto a grande maioria, 33\%, atua como tutor de um a três anos. Do restante, $30 \%$ atuam a menos de um ano e $20 \%$ de três a cinco anos. Desse modo, pode-se descrever um público majoritariamente atuante em instituições públicas de educação a distância e com até três anos de experiência.

A terceira pergunta do questionário aponta para uma problemática séria no âmbito da $\mathrm{EaD}$ e que incide diretamente sobre a qualidade da educação nessa modalidade de ensino: a formação dos tutores de educação a distância. Aos respondentes foi perguntado se receberam algum treinamento para atuar enquanto tutor de $\mathrm{EaD}$ e, embora termos como resultado que a absoluta maioria, 83\%, recebeu treinamento, cruzando os dados temos que, daqueles que $80 \%$ dos que trabalham em instituição privada não receberam treinamento. Conclui-se dessa forma que a maioria dos tutores que não recebeu treinamento atuam em instituições privadas de ensino.

Levanta-se, portanto, a questão sobre os parâmetros de qualidade da educação a distância, uma vez que o profissional não treinado para lidar com as especificidades do 


\section{SEMINÁRIO DE PESQUISA EM CIÊNCIAS HUMANAS - SEPECH \\ Humanidades, Estado e desafios didático-científicos \\ Londrina, 27 a 29 de julho de 2016}

processo de aprendizagem nessa modalidade pode colocar em risco a qualidade da educação oferecida, tendo em vista que o tutor virtual, como apontam Belloni (2006 apud CAVALCANTE FILHO; SALES; ALVES, 2012) e Rodriguez (1993 apud PRETI, 2003), exerce forte influência no desempenho da aprendizagem e na taxa de evasão.

Já sobre a prática da tutoria nos cursos a distância, a quarta questão discorreu sobre as atividades pedagógicas desenvolvidas pelos respondentes no sistema de tutoria de sua instituição. Foram elencadas sete atribuições dos tutores na $\mathrm{EaD}$ e mais uma opção que se referia a outras atividades. Nessa pergunta os tutores poderiam marcar quantas respostas fossem necessárias. De um total de trinta respondentes, verifica-se que acompanhar o andamento dos alunos é a atividade com incidência na quase totalidade da função dos tutores pesquisados (29 vezes). A segunda atividade mais desenvolvida pelos tutores pesquisados é estimular a participação nas atividades dos alunos (28 vezes). Entretanto, duas outras atribuições listadas nesta pergunta recaem sobre o estímulo à participação dos alunos nas atividades desenvolvidas, quais sejam: organizar espaços de interação e lançar perguntas provocadoras para discussões no fórum; ou seja, ambas as atividades, se desenvolvidas possibilitam que o aluno sinta-se motivado a participar nas interações e discussões realizadas. Contudo, quando cruzamos essas três atividades (estimular a participação nas atividades dos alunos, organizar espaços de interação e lançar perguntas provocadoras para discussões no fórum), observa-se que dos 28 tutores que dizem estimular seus alunos a participarem nas atividades, somente 15 também se dedicam à organização de espaços para interação e a lançar perguntas provocadoras para serem discutidas em fóruns de aprendizagem.

Tal análise aponta para uma falta de entendimento entre os tutores sobre quais atividades realmente estimulam a participação de seus alunos. Essa situação está ligada à problemática da questão seguinte. A quinta pergunta do questionário avaliou a necessidade de uma formação mais específica para os profissionais que atuam enquanto tutores na EaD. A grande maioria dos tutores pesquisados, $83 \%$, respondeu que sim, que se faz necessário uma formação específica para os profissionais; enquanto apenas 3\% acreditam não haver necessidade de tal formação e 14\% disseram talvez.

Os dados obtidos a partir desse questionamento apontam, sobretudo, para a insatisfação dos tutores em relação à formação que receberam das instituições em que atuam, pois, quando cruzamos os dados dos tutores que receberam formação para atuar como tutores na EaD com a necessidade de uma formação mais específica, 85\% dos tutores que receberam treinamento consideram necessária uma formação mais específica, enquanto o restante, $15 \%$, responderam não ter certeza. A maioria dos respondentes julgou ser necessária formação específica por termos um perfil de tutores que, em sua maioria, estão a menos de três anos atuando no ensino a distância. Contudo, os 12 tutores respondentes que atuam na $\mathrm{EaD}$ a mais de três anos, em sua totalidade, responderam ser necessária a formação mais específica para o tutor virtual. Portanto, não se trata de falta de experiência, mas da necessidade de conhecimento.

O questionário apresentou ainda neste primeiro momento de questões gerais e relacionadas ao sistema de tutoria-uma questão sobre elementos que possam ser considerados essenciais para a formação de um tutor que permita que esse seja apto a atuar com qualidade na modalidade de $\mathrm{EaD}$. A questão oferecia sete elementos e pedia para que os respondentes os enumerassem em ordem de importância. 


\section{SEMINÁRIO DE PESQUISA EM CIÊNCIAS HUMANAS - SEPECH \\ Humanidades, Estado e desafios didático-científicos \\ Londrina, 27 a 29 de julho de 2016}

Observou-se que, possuir conhecimento pedagógico do processo de aprendizagem foi o elemento que apareceu um maior número de vezes, como sendo o primeiro elemento considerado essencial para a formação de um tutor. O que corrobora com a hipótese de que as teorias da aprendizagem devem ser centrais para a formação e boa atuação da tutoria e qualidade da $\mathrm{EaD}$. No entanto, a especialização em docência no ensino superior ou em outra área pedagógica aparece, dentre os sete elementos, como o sexto mais importante; do que podemos depreender que os respondentes entendem que o conhecimento pedagógico deve advir dos cursos de formação de tutores oferecidos como treinamento pelas próprias instituições.

As próximas cinco questões foram elaboradas com o objetivo de identificar como a formação do tutor perpassada pelas diferentes abordagens da aprendizagem pode ser importante para a sua atuação e qualidade do processo de ensino e aprendizagem.

A primeira questão centrou-se na motivação das capacidades de pensar e agir e os tutores foram questionados sobre práticas que estimulam os alunos no processo de aprendizagem. Dos 30 tutores pesquisados, 20 disseram que "sempre" estimulam seus alunos para que o processo de ensino-aprendizagem ocorra, enquanto 10 disseram "às vezes" e o mais interessante é que nenhum disse que "nunca".

A segunda questão centrou-se no conceito de interações sociais de Vygotsky e procurou verificar se os tutores estimulam seus alunos para que ocorra a interação no processo de aprendizagem. Dos 30 tutores pesquisados, 21 disseram que "sempre" estimulam seus alunos para interagirem no fórum, enquanto 9 disseram "às vezes". Mais uma vez nenhum disse que "nunca".

$\mathrm{Na}$ terceira questão os tutores foram apresentados ao conceito de linguagem em Vygotsky e questionados sobre a promoção de bons diálogos no ambiente virtual. Dos 30 tutores pesquisados, 15 disseram que "sempre" a linguagem utilizada por ele e seus alunos no ambiente virtual de aprendizagem proporciona bons diálogos ajudando na construção do conhecimento, enquanto 15 disseram "às vezes". Mais uma vez nenhum disse que "nunca".

As próximas duas perguntas referiam-se a pedagogia humanista de Paulo Freire. A primeira explorou se os tutores consideram suas ações compatíveis com a prática freiriana no sentido de se apropriar dos saberes que emergem de sua própria prática. A maioria dos respondentes, $57 \%$, ou seja, 17 tutores entendem que o trabalho deles é compatível com a ideia de Freire, $40 \%$ - 12 pessoas disseram que o trabalho ás vezes é compatível com as ideias de Freire e 1 respondente entende que o trabalho dele não é compatível com as ideias acima apresentadas de Paulo Freire. Esse respondente atua há mais de cinco anos como tutor, atua na rede pública de ensino e recebeu treinamento para tutores.

A segunda pergunta relaciona-se à criatividade e inovação críticas na prática educativa, como apresentada por Paulo Freire. Nessa questão, 50\% da amostra entende que dar lugar a criatividade, inovação e inovação são compatíveis com a sua prática e $47 \%$ disseram que seu trabalho às vezes é compatível com essas ideias. Apenas para 1 respondente a criatividade, inovação e autonomia não constituem a prática de seu trabalho como tutor.

As próximas três perguntas, sobre a contribuição da psicanálise para $\mathrm{EaD}$, partiram da exploração de dois conceitos de origem psicanalítica apropriados no 


\section{SEMINÁRIO DE PESQUISA EM CIÊNCIAS HUMANAS - SEPECH \\ Humanidades, Estado e desafios didático-científicos \\ Londrina, 27 a 29 de julho de 2016}

entendimento da relação tutor-aluno na $\mathrm{EaD}$, a saber: o conceito de autonomia e o conceito de transferência.

$\mathrm{Na}$ primeira questão os tutores foram convidados a responder se acreditam que o tutor virtual deve assumir o papel de autoridade no processo de ensino a distância. Apenas $7 \%$ não considera essa afirmação verdadeira. A grande maioria se divide, contudo, ou seja, $43 \%$ e $50 \%$, respectivamente, entre os que acreditam que o tutor virtual deve sim assumir o papel de autoridade no processo de ensino a distância e os que responderam que talvez essa atitude seja a correta; o que aponta para uma maior aceitação do que rejeição da compreensão de uma premissa advinda das relações entre psicanálise e EaD.

$\mathrm{Na}$ pergunta seguinte os tutores foram questionados se se consideram autoridade no processo de ensino a distância. A grande maioria, 77\%, respondeu que sim, sempre; $17 \%$ responderam que às vezes consideram-se autoridade nesse processo; e apenas $6 \%$ responderam não se considerarem autoridade no processo de ensino a distância.

Por fim, os sujeitos da pesquisa foram questionados sobre a possibilidade do conhecimento em psicanálise beneficiar sua própria atuação como tutor e contribuir para ajudá-los a potencializar o aprendizado de seus alunos. Mais uma vez, a grande maioria, $73 \%$, respondeu que sim; enquanto $23 \%$ responderam que talvez o conhecimento em psicanálise possa auxiliá-los; e apenas $4 \%$ responderam não acreditar que esse conhecimento seja potencializador do aprendizado se seus alunos.

Nota-se, portanto, que para a maioria dos tutores, o conhecimento acerca das contribuições da psicanálise para as relações tutor-aluno na modalidade de EaD é visto de maneira positiva e desejado como conteúdo a ser apreendido em sua formação, corroborando com a hipótese de que os sistemas de tutoria são carentes de uma maior fundamentação teórica nos aspectos que incidem sobre o processo pedagógico de ensino e aprendizagem.

\section{CONSIDERAÇÕES FINAIS}

Através dos dados levantados, foi possível perceber que há diversas atividades e funções do tutor virtual que perpassam pelas teorias da aprendizagem e que precisam ser desenvolvidas para o bom desempenho na função.

Faz-se necessário, portanto, que tais especificidades requeridas para a boa atuação do tutor na $\mathrm{EaD}$ sejam contempladas em cursos de formação e treinamento. $\mathrm{O}$ quadro que se desenhou a partir da análise dos dados levantados com a aplicação do questionário, entretanto, aponta para necessidade das instituições de ensino pensar uma formação e um treinamento adequado para essa função, que se mostra tão importante para a educação a distância. A oferta nem sempre recorrente e a baixa qualidade dessa formação, como se depreende da análise dos dados do questionário, incide diretamente sobre uma carência desses profissionais para lidar com as adversidades do dia a dia do tutor virtual, e mesmo com a competência mais elementar da tutoria: a interação.

Percebe-se que o papel do tutor na educação a distância refere-se, na maioria das vezes, inclusive na percepção dos próprios tutores que participaram desta pesquisa, às competências da docência, que incluem habilidades, atitudes e maneiras de atuar na interação virtual, mas, sobretudo, incluem também conhecimentos pedagógicos acerca do desenvolvimento das capacidades básicas dos alunos. Portanto, conclui-se que, para 


\section{SEMINÁRIO DE PESQUISA EM CIÊNCIAS HUMANAS - SEPECH \\ Humanidades, Estado e desafios didático-científicos \\ Londrina, 27 a 29 de julho de 2016}

além das competências técnicas da função de tutoria, esse papel requer o conhecimento teórico pedagógico que incide diretamente sobre a capacidade de mediação e desenvolve a sensibilidade do tutor para identificar e diagnosticar as dificuldades de aprendizagem inerentes ao ambiente virtual.

Há de se destacar que a manutenção do interesse do aluno em um curso online e a eficiência de sua aprendizagem está diretamente relacionada ao sucesso da interação com os tutores, bem como com a boa atuação desse profissional, e entende-se aqui, que tais características podem ser desenvolvidas por meio de programas de formação e treinamento que incluam em seu escopo o estudo sobre as teorias da aprendizagem.

Contudo, este trabalho não encerra as discussões acerca das implicações do conhecimento pedagógico na atuação do tutor virtual e na qualidade da Educação a Distância, mas permite que a busca pelo conhecimento apresente novas possibilidades de interpretação da relação tutor-aluno e que novas pesquisas possam abarcar a importância das contribuições teóricas sobre a aprendizagem em diferentes perspectivas.

\section{REFERÊNCIAS}

CAVALCANTE FILHO, Antonio; SALES, Viviani Maria Barbosa; ALVES, FrancioneCharapa. A identidade docente do tutor da educação a distância. In: SIED Simpósio Internacional De Educação A Distância 2012 / Encontro De Pesquisadores Em Educação A Distância, 2012, São Carlos: UFSCAR - Universidade Federal de São Carlos, 2012. Disponível em: $<$ http://sistemas3.sead.ufscar.br/ojs/Trabalhos/295-1015-1ED.pdf $>$. Acesso em: 28 ago. 2015.

FARIA, Elísio Vieira de. O tutor na Educação a Distância: a construção de conhecimentos pela interação nos ambientes midiáticos no contexto da educação libertadora. Scientia FAER, Olímpia, ano 2, v. 22, p. 28-37, 1. sem. 2010. Disponível em: $<$ http://www.faer.edu.br/revistafaer/artigos/edicao2/elisio.pdf $>$. Acesso em: 13 mar. 2015.

FREIRE, Paulo. Conscientização: teoria e prática da libertação: uma introdução ao pensamento de Paulo Freire. São Paulo: Cortez e Moraes, 1979.

Pedagogia da Esperança: Um Reencontro com a Pedagogia do Oprimido. São Paulo: Paz e Terra, 1997.

OLIVEIRA, Carmen Lúcia de Araújo Paiva. Afetividade, Aprendizagem e Tutoria Online. Revista EDaPECI, São Cristóvão, v. 3, n. 3, dez. 2009. Disponível em: $<$ http://www.seer.ufs.br/index.php/edapeci/article/view/565/469>. Acesso em: 25 fev. 2015.

OLIVEIRA, Gleyva Maria Simões de. O sistema de tutoria na educação a distância. Disponível em: <http://www.uab.ufmt.br/uab/images/artigos_site_uab/tutoria_ead.pdf $>$. Acesso em: 31 ago. 2015. 


\section{SEMINÁRIO DE PESQUISA EM CIÊNCIAS HUMANAS - SEPECH \\ Humanidades, Estado e desafios didático-científicos \\ Londrina, 27 a 29 de julho de 2016}

OLIVEIRA, Marta Kohl de. Vygotsky: aprendizado e desenvolvimento; um processo sócio-histórico. São Paulo: Scipione, 2010. (Série Pensamento e ação no Magistério).

PESSOA, Ilene Figueiredo; BORGES, Sonia Xavier de Almeida. Educação online: a transferência na relação professor-aluno. B. Tec. Senac, Rio de Janeiro, v. 39, n. 3, p. 108-123, set./dez. 2013. Disponível em: $<$ http://www.senac.br/media/53512/os_boletim_web_8.pdf $>$. Acesso em: 2 jun. 2015.

PRETI, Oresti. O estado da arte sobre "tutoria": Modelos e teorias em construção. In: PRETI, Oreste; OLIVEIRA, Gleyva M. S. de. Relatório de Pesquisa "O sistema de Orientação Acadêmica no curso de Pedagogia a distância da Universidade Federal de Mato Grosso". Projeto "Les susthémes d'appui à l'étudiant dans Le domaine de la Formation à Distance: le tutorat". Programa CAERENAD - Télé-université du Québec, Canadá, agosto 2003. Disponível em: < http://www.uab.ufmt.br/uploads/pcientifica/tutoria_estado_arte.pdf $>$. Acesso em: 31 ago. 2015.

RESENDE, Regina Lúcia Sartorio Marinato de. Fundamentos Teórico-Pedagógicos para EAD. In: CONGRESSO INTERNACIONAL DE EDUCAÇÃO A DISTÂNCIA, 12, 2005, Florianópolis. Anais do 12- Congresso Internacional de Educação a Distância. Florianópolis: ABED, 2005. Disponível em: $<$ http://www.abed.org.br/congresso2005/por/pdf/055tcb5.pdf $>$. Acesso em: 4 jun. 2015.

SOUZA, Carlos Alberto de. et al. Tutoria na Educação a Distância. In: CONGRESSO INTERNACIONAL DE EDUCAÇÃO A DISTÂNCIA - ABED, 11., 2004, Salvador. Anais do $1^{\circ}$ Congresso Internacional de Educação a Distância. Salvador: ABED, 2004. Disponível em: <http://www.abed.org.br/congresso2004/por/htm/088-TCC2.htm>. Acesso em: 10 maio 2015.

TEIXEIRA, Janaina Angelina; COSTA E SILVA, Ana Paula; CORDEIRO, Bernadete Moreira Pessanha. Formação de Professores-Tutores sob a Perspectiva da Colaboração, Interação e Aprendizagem Significativa na Educação a Distância. In: CONGRESSO INTERNACIONAL ABED DE EDUCAÇÃO A DISTÂNCIA CIAED, 19, 2013, Salvador. Disponível em: $<$ http://webcache.googleusercontent.com/search?q=cache:xxKfs3iYMjcJ:www.abed.or g.br/congresso2013/trabalhos/304.doc $+\& \mathrm{~cd}=2 \& \mathrm{hl}=\mathrm{pt}-\mathrm{BR} \& \mathrm{ct}=\mathrm{clnk} \& \mathrm{gl}=\mathrm{br}>$. Acesso em: 5 jun. 2015.

VYGOTSKY, Lev Semenovich. Pensamento e Linguagem. 2. ed. São Paulo: Martins Fontes, 1998. 